Branka Kalenić Ramšak

Universidad de Ljubljana

\title{
EJEMPLOS DE LA RECEPCIÓN CREATIVA \\ DE LA LITERATURA ESPAÑOLA \\ EN LA LITERATURA ESLOVENA
}

Palabras clave: literatura española, literatura eslovena, influencias, recepción creativa

\section{Introducción}

España y Eslovenia son dos países geográfica y mentalmente alejados. La distancia física se ha manifestado también a lo largo de la historia en sus escasas relaciones políticas, económicas, culturales. En esloveno existe la frase hecha «es un pueblo español», que es un préstamo del alemán (spanische Dörfer) y procede del período de Carlos V (Carlos I de España), durante la primera mitad del siglo XVI, cuando en los países germánicos se promovían algunas costumbres españolas, incomprensibles para sus gentes (Oman, 2010: 85). Hoy en día, cuando la realidad ha cambiado por completo y las relaciones hispanoeslovenas se han intensificado, sobre todo en el área cultural, la expresión mencionada sigue utilizándose sólo con un significado general para todo lo desconocido, incomprensible o de poca importancia, sin referencias a lo español.

En la literatura, el cine, la pintura y otros campos artísticos Eslovenia y España hoy viven un espléndido intercambio de ideas y colaboraciones, se realizan traducciones de diferentes textos, a cada paso surgen proyectos comunes. El lector intelectual esloveno conoce bastante la literatura española, sea a través de la lectura de los textos en español ${ }^{1}$, sea a través de las numerosas traducciones publicadas en los últimos años; al revés la situación es menos favorable, porque, desgraciadamente, la literatura eslovena todavía sigue siendo una desconocida para el vasto público español, aunque en los últimos años ya se han publicado traducciones de varios escritores eslovenos.

Pero en el presente artículo nos interesa la influencia creativa de la literatura española sobre la eslovena. Es muy difícil detectar tales influencias entre los autores contemporáneos, cuando, gracias a la globalización y un mar de intertextualidades, casi todo texto nuevo provoca un efecto déjà $v u$. Sin embargo, parece que la literatura española ha tenido una influencia invisible, casi secreta, tanto temática como formal sobre algunos autores eslovenos. Estas relaciones pasaron prácticamente desapercibidas hasta que los primeros hispanistas salieron del Departamento de Hispánicas de la Facultad de Filosofía y Letras de la Universidad de Ljubljana en los años noventa del siglo pasado y realizaron varios estudios alumbrando la recepción creativa de la literatura española entre distintos escritores eslovenos.

En los últimos años, en varias regiones eslovenas, el español ya es la segunda lengua extranjera de la escuela primaria o secundaria. 
Uno de los primeros textos sobre el tema propuesto es de Damjana Pintarič (1993) que estudió al autor Andrej Hieng (1925-2000), narrador y dramaturgo de la segunda mitad del siglo XX, en cuyos dramas la autora ha mostrado la simbología de los motivos españoles en relación con la realidad eslovena. Se trata de un ciclo de dramas psicológicos en los que el autor utiliza el material histórico español para destacar la tensión entre lo ideal y lo real, y consecuentemente las frustraciones del ser humano por no poder realizar sus ideales.

No debe sorprender que quien más recepción creativa entre los autores eslovenos ha tenido fue Cervantes con el Quijote, que logró captar el misterio y la complejidad de la vida y también supo explorar la misteriosa relación entre ficción y realidad que subyace en el alma de la novela.

A continuación se presentarán también algunas formas tradicionales de la poesía española con referencias al mundo hispano y la poesía sugestiva de García Lorca que fueron releídas de un modo creativo e incorporadas en las obras de algunos poetas eslovenos.

\section{Los inicios de la literatura eslovena}

Los inicios de la literatura eslovena y castellana son parecidos y se relacionan con la predicación del Evangelio. El pueblo esloveno luchó por su lengua y cultura a lo largo de mucho tiempo, prácticamente desde los siglos VI y VII. Los eslovenos, en su larga historia, siempre fueron dominados por potencias extranjeras, la germánica o la austrohúngara, la italiana, la francesa o la serbocroata, hasta que en el año 1991 se consiguió la independencia política, al proclamar la independencia de la República de Eslovenia.

Los manuscritos más antiguos que se conservan datan del siglo X. Se trata de los manuscritos Brižinski spomeniki (Monumentos de Freising), procedentes del obispado de Freising (en esloveno Brižinj), en Baviera. Los documentos constan de 169 pergaminos que datan de finales del siglo X y principios del XI, posiblemente entre 972 y 1039; son textos religiosos, la mayoría escritos en latín; sólo tres pergaminos están escritos en esloveno. El primero y el tercero hablan de la confesión, el segundo es el sermón que versa sobre el pecado y la penitencia. No se trata sólo de los documentos eslovenos más antiguos sino también de los textos eslavos más antiguos.

No se conservan documentos escritos posteriores en idioma esloveno a lo largo de cuatro siglos, lo cual se debe probablemente a la dominación de la dinastía de los Habsburgo, que gobernó a los eslovenos desde 1100 hasta prácticamente el final de la Primera Guerra Mundial (1918), cuando se formó el primer estado yugoslavo. Hubo un breve período de dominación francesa a principios del siglo XIX (1809-1813).

Del siglo XV se han guardado los manuscritos religiosos procedentes del convento de Stična y de las ciudades Celovec (la actual Klagenfurt, en Austria) y Čedad (Cividale, hoy ciudad de Italia). En 1550 Primož Trubar, un pastor protestante, escribió los dos primeros libros en esloveno: el Abecedarium y el Catechismus. El primero es un abecedario 
de ocho páginas, el segundo contiene los principales conceptos del catecismo protestante, algunas oraciones y canciones religiosas.

\section{Don Quijote en esloveno}

Las primeras noticias sobre las andanzas caballerescas del famoso hidalgo manchego llegan al mundo esloveno de modo indirecto, a través de traducciones alemanas y francesas. No se trata realmente de una recepción crítica o literaria sino de menciones parciales de la novela caballeresca de Cervantes ${ }^{2}$. En la segunda mitad del siglo XVIII los principales humanistas de la Ilustración eslovena, Žiga Zois (1747-1819) y Anton Tomaž Linhart (1756-1795, autor de la primera comedia en esloveno), leyeron el Quijote en su traducción francesa y lo mencionaron en varias cartas (Smolej, 2006: 237).

Las primeras traducciones del Quijote al esloveno fueron parciales porque se tradujeron sólo los capítulos más conocidos, en versiones adaptadas y abreviadas. Estas traducciones datan de la segunda mitad del siglo XIX y se hicieron siempre a partir de otras lenguas extranjeras, nunca directamente del español. Don Quijote se presenta al público esloveno por primera vez en 1864, cuando en la revista Goriški letnik (El anuario de Gorizia) se publican algunos capítulos adaptados: Don Kišot in njegov ščitnik Sanho Pansa (Nekoliko prizorov v okrajšku) o Don Quixote y su protector Sanho Pansa (Algunas escenas abreviadas) del autor Fran Zakrajšek, maestro en la ciudad de Gorizia. En 1890, en un libro de relatos, aparece una versión adaptada para jóvenes cuyo autor es Fran Nedelko: Don Kišot iz la Manhe, vitez otožnega lica (Don Quijote de la Mancha, el caballero de la triste figura). En estas dos primeras traducciones el texto original únicamente sirvió para fines didácticos, porque ni siquiera aparece el nombre de Cervantes (Markič, 2007).

Los intelectuales eslovenos conocían el texto completo de la novela de Cervantes ya antes de la primera traducción completa al esloveno (en 1935, traducción hecha por Stanko Leben), sobre todo leyendo traducciones alemanas, francesas y también rusas e italianas. Gracias a la reinterpretación del Quijote por parte de los románticos alemanes, los románticos y realistas eslovenos se inspiraron también en la novela de Cervantes y la incluyeron en su mundo literario.

\section{El caso Prešeren}

\section{1.}

Entre los primeros intelectuales eslovenos que estudiaron sistemáticamente la literatura italiana, española y portuguesa estuvo Matija Čop (1797-1835), que llegó a dominar diecinueve lenguas extranjeras. En su biblioteca privada poseía cuatro ejemplares del Quijote, dos en francés, uno en italiano y uno en español. Čop, pilar intelectual de los inicios del siglo XIX, en los que empezó a formarse una nueva generación romántica

\footnotetext{
2 Otros textos de Cervantes, ya se trate de sus obras de teatro, prosa corta o poesía, no fueron conocidos ni leídos en aquel entonces. Algunas Novelas ejemplares se tradujeron entre 1920 y 1948, la traducción íntegra es de 1951.
} 
eslovena, fue también maestro del poeta France Prešeren (1800-1849), quien fue su discípulo predilecto:

Entre los autores del siglo XVII cuyas obras enriquecieron la biblioteca del erudito figuran los nombres más importantes, como Cervantes, Góngora, Quevedo, Lope de Vega, Tirso, Calderón, y otros menos sonantes como Juan de Jáuregui, Rojas Zorrilla, Agustín Moreto, etc. Según esto, no habrá que extrañarse que el barroco literario español y portugués deje huellas también en la poesía de Prešeren. (Oman, 2010: 90)

Prešeren es considerado el poeta más importante de la poesía eslovena y al mismo tiempo uno de los más importantes románticos europeos:

Prešeren ha sido hombre de su tiempo, no podía estar ajeno a las concepciones románticas que exaltaban la libertad individual y de los pueblos, dos pilares firmes de su obra poética. Se trata de una obra que no se agota en su valor estético, sino que, al mismo tiempo, revela aspectos importantes de un pueblo oprimido que sólo había conocido una primavera políticocultural durante un breve período napoleónico ${ }^{3}$. (Prenz, 2003: 172)

Čop hizo descubrir a Prešeren las literaturas italiana y española, poco conocidas entre los intelectuales de aquel entonces. De modo que el poeta romántico esloveno también incluyó a Cervantes y a otros autores barrocos españoles en su poesía. Špela Oman investiga las resonancias de la poesía española y portuguesa en la poética de France Prešeren; ya ha publicado en Verba Hispanica 18 (2010) un artículo sobre la recepción del barroco español y portugués en la poesía de Prešeren. Se trata de un estudio muy revelador, una mirada íntegramente innovadora sobre la creación de Prešeren, que magistralmente supo incorporar en su poética romántica los temas, los motivos y las formas de los autores españoles: de Lope de Vega, Miguel de Cervantes, Francisco de Quevedo, Luis de Góngora, Calderón de la Barca, etc.

Prešeren se refiere a Cervantes en su poema Glosa. El tema es la reflexión sobre el oficio poético, que nunca asegura el bienestar económico de su autor. En la primera décima menciona, entre otros grandes poetas, también al autor del Quijote como uno de los ilustres representantes del parnaso poético universal que, a pesar de su autoridad literaria, vivió y murió en la miseria material ${ }^{4}$. Prešeren escogió la forma española de la glosa, que está compuesta en su caso de cuatro décimas (en el octosílabo llamado octosílabo español) que comentan los versos iniciales del cuarteto y cuyos versos aparecen al

\footnotetext{
Prenz se refiere al período napoleónico (1809-1813), cuando los franceses ocuparon las regiones de Europa central y del este, entre ellas también la eslovena, y se formaron las Provincias Ilirias con sede en Ljubljana. Los franceses favorecieron la enseñanza del esloveno en los colegios, la publicación de libros en esloveno, el uso público del idioma, de modo que la lengua eslovena adquirió una nueva posición en la sociedad. Cuando en 1813 Austria declaró de nuevo la guerra a Napoleón e invadió las Provincias, los franceses fueron expulsados de la región y los eslovenos volvieron a ser nuevamente dominados por los austríacos en el marco del Imperio austrohúngaro.

4 En una versión del poema, publicada en el almanaque de la época Krajnska čbelica (Abeja carniola) en 1834, aparece una nota en la que se añade el nombre del autor del Quijote. Este hecho nos explica el grado de ignorancia del lector común de la época, que no estaba familiarizado con el texto de Cervantes.
} 
final de cada décima. La forma de la glosa española fue acogida por los poetas franceses y alemanes en el siglo XVII. Sin embargo, Boris A. Novak (1995: 60) cree que Prešeren podría haberse inspirado en la glosa que aparece en el capítulo XVIII de la segunda parte del Quijote. En las dos glosas encontramos similitud temática: resignación, desilusión, falsa esperanza, fugacidad de la vida (tempus fugit), la muerte salvadora.

Estos temas barrocos son reutilizados por Prešeren también en sus sonetos, particularmente en los siete sonetos titulados Sonetos de la infelicidad (1847):

Lo barroco alcanza su cima en el ciclo Sonetos de la infelicidad, cuyo título, más que el estado de ánimo del poeta, expresa la noción barroca del mundo. Ésta última constituye el eje vertebrador de los seis sonetos, puesto que el ciclo recoge casi de manera enciclopédica todo un compendio de temas y motivos de tono grave de modo que cada soneto encaja en el mosaico barroco. La temática barroca desemboca en el soneto Memento mori, que aborda uno de los temas barrocos por excelencia: el «sic transit gloria mundi». (Oman, 2010: 90-91)

Así, el último soneto, Memento mori, constituye una síntesis reflexiva sobre la vanidad del mundo y la fugacidad de la vida del poeta:

Breve es el tiempo de nuestra vida. ¡Cuántos amigos yacen bajo tierra! La puerta de la tumba está abierta pero no hay quien revele el día.

Ni la espléndida pelliza ni el oro jamás podrán de la muerte salvarnos; al ladrón de la vida no lo calmamos con la alegría y el verso sonoro.

Quien adora ciegamente la vida y salta de alegría en alegría, sabrá que siempre acecha la muerte.

Quien ahora alegre entona antes del ocaso, desde el ataúd, nos hará mudo recordar su suerte.

(Trad. J. O. Prenz, 2003: 77)

\section{2.}

France Prešeren acogió con mucho entusiasmo la forma del romance español y la adaptó a la estructura de la lengua eslovena -utilizó el verso octosilábico y, dentro de varias posibilidades rítmicas del romance, utilizó el troqueo, que es una estructura monorrítmica, sin embargo parece óptima para la transformación al esloveno (Novak, 2011: 124). Prešeren también respetó la asonacia en los versos pares. De este modo adoptó la forma original del romance español a la tradición métrica eslovena y formó un modelo 
ideal de adaptación de forma poética de una lengua a otra.

Escribió varios romances con la forma española: Hčere svèt (El mundo de la hija), el romance de la poesía temprana sobre el tema amoroso; Učenec (Discípulo); Dohtar (Médico); el famoso romance narrativo sobre la soberbia femenina: Turjaška Rozamunda (Rosamunda de Turiak). El romance empieza con la descripción del patio del castillo de Turiak, donde el padre de Rosamunda recibe a sus galanes:

Hrast stoji v turjaškem dvóri,
vrh vzdiguje svoj v oblake,
v senci pri kamniti mizi
zbor sedi gospode žlahtne,
ker Turjačan spet gostuje
Rozamundine snubače

(Prešeren, 1969: 23)

El verso es octosílabo trocaico con asonancia en los versos pares; a lo largo del romance la vocal acentuada de la última sílaba de cada verso es la vocal a.

\section{3.}

Otra referencia al mundo hispánico la encontramos en la balada Pesem od lepe Vide (De la hermosa Vida) que simboliza el eterno descontento humano con la realidad, la falsa ilusión de que el bienestar puede sustituir el amor. El tema proviene de la balada bizantino-balcánica del siglo XII en la que la bella mujer es raptada por un sarraceno ${ }^{6}$. Prešeren adaptó el antiguo tema a la estética romántica. El negro ${ }^{7}$ de su balada quiere llevar a la hermosa Vida a la corte de la reina de España para que amamante al principito español, al futuro emperador. El oro prometido le convence, la hermosa Vida abandona a su familia, pero en la corte española vive su terrible tragedia personal. En esta balada el reino español simboliza un lugar lejano, al otro lado del gran mar, un país de gran importancia, lujoso y de muchas riquezas, pero que a la hermosa Vida sólo le produce una pena profunda porque el oro no puede suplirle el amor por su hijo y su marido.

\section{Del romanticismo al realismo}

La segunda mitad del siglo XIX fue para la historia y literatura eslovenas una época muy importante. Hasta 1848 el gobierno austrohúngaro absolutista de Metternich prohibía el uso público de la lengua eslovena imponiendo un rígido sistema de censura. Con la caída del dicho gobierno subió al poder el emperador Fernando, quien otorgó a los pueblos del imperio una relativa libertad política y cultural. Los eslovenos obtuvieron el derecho

\footnotetext{
Se alza la encina en el patio / con su copa hasta las nubes; / bajo la sombra, a la mesa / se sientan nobles varones, / dignos huéspedes de Túriak, / galanes de Rosamunda (Prešeren, 2003: 37; trad. J. O. Prenz).

6 Los eslavos temían a los turcos que navegaban por el Mediterráneo, robaban las tierras y secuestraban a las mujeres.

7 En la traducción de Juan Octavio Prenz el negro se convierte en el moro.
} 
a utilizar públicamente su lengua, pero pronto se hicieron evidentes las consecuencias del riguroso sistema anterior. Faltaban manuales en esloveno, por lo que el sistema educativo frecuentemente se vio obligado a utilizar los libros en alemán. Consecuentemente los intelectuales fundaron sociedades nacionales cuyas editoriales publicaban libros, folletos, periódicos, material propagandístico y organizaban conferencias y tertulias literarias. Los acontecimientos políticos despertaron el sentimiento nacional entre los eslovenos.

Cuando el romanticismo dejó paso al realismo, se produjo una ruptura entre los conservadores, que defendían el viejo sistema político y cultural, y los liberales, que iban aceptando las ideas nuevas. Precisamente en los escritos de los liberales que luchaban contra el predominio germánico y apoyaban la independencia cultural y lingüísticoliteraria eslovenas encontramos ejemplos, sobre todo en la prosa satírica, en los que se menciona la novela de Cervantes.

La generación literaria que recibió las premisas estéticas del realismo buscó modelos en diferentes autoridades narrativas extranjeras, entre otros también en la novela de Cervantes, a pesar del hecho de que todavía no existía una traducción íntegra del Quijote en esloveno. En su empeño por mejorar la calidad de la prosa eslovena, de elevarla de un nivel folclórico-costumbrista a un nivel literario superior, de transmitir los problemas de la realidad eslovena de aquel entonces de acuerdo con las proposiciones estéticas literarias, se volvieron hacia la historia del Quijote. Algunos tomaron de ella su aspecto humorístico-grotesco, otros su relación entre lo ideal y lo real, y un tercer grupo simplemente se dejó seducir por su mundo irreal y sus técnicas narrativas. Barbara Pregelj (2006) considera que el interés por la obra de Cervantes puede explicarse dentro del contexto del nacimiento de la novela eslovena. Algunos autores comparan además el estado mental de la sociedad eslovena con la enfermedad de don Quijote.

Entre los autores que interpretaron a su modo el Quijote está también Ivan Cankar (1876-1918), autor modernista de relatos y obras de teatro que poseía en su biblioteca traducciones alemanas de la novela de Cervantes. Frecuentemente Cankar se identifica con el idealismo quijotesco que adopta como su propio modus vivendi (en la novela autobiográfica Novo življenje (La nueva vida), 1908) o guarda el eterno idealismo de don Quijote refiriéndose a las injusticias políticas que el pueblo esloveno tuvo que soportar bajo la dominación germánica (Krpanova kobila (La jaca de Krpan), 1907).

En el drama Hlapci (Sirvientes), tragedia política, obra comprometida, de fuerte mensaje anticlerical ${ }^{8}$, la primera escena del segundo acto se parece al capítulo VI de la primera parte del Quijote, El escrutinio de la biblioteca: el director del colegio y uno de los maestros, ambos severos antiliberales, repasan los libros de la biblioteca del colegio echando a la hoguera los libros demasiado liberales (por ejemplo la poesía liberal del poeta Anton Aškerc, 1856-1912). Como el cura y el barbero de Cervantes, que salvaron algunos libros de la biblioteca de don Quijote, los dos profesores de Cankar salvan unas poesías del romántico France Prešeren y las del romántico-realista Simon Gregorčič (1844-1906), porque después de la muerte sus ideas ya no parecen tan peligrosas. Pero

8 El drama fue escrito en 1909, pero prohibido por la censura. Por eso fue representado en 1919, ya después de la muerte de Cankar, primero en Trieste y luego en Ljubljana. 
cuando cogen en sus manos los libros de Ivan Cankar, los echan decididamente a la hoguera por sus ideas extrañas que ni siquiera parecen liberales, diciendo que sería oportuno rezar por la salvación de su alma. De modo que Cankar no salva sus textos como lo hizo Cervantes con su novela pastoril La Galatea sino los destruye en el fuego. Este hecho tiene en el contexto esloveno de entonces una fuerte simbología política.

\section{García Lorca y Udovič}

Otro ejemplo de la recepción creativa de la literatura española en la eslovena es la poesía de Federico García Lorca. El poeta andaluz es uno de los autores españoles más conocidos, traducidos, leídos y recitados en el mundo; también en la literatura eslovena. Su imagen de juglar moderno se ha convertido en un fenómeno cultural hispánico, o mejor dicho, en uno de los tópicos españoles. Su obra poética ha ido cobrando dimensiones de obra clásica española, comparable a la de Cervantes; su lenguaje poético, brotado de la vieja tierra mediterránea, nos ha hechizado a todos y su metáfora presagiosa todavía nos estremece al hacernos sentir el misterio de la vida y de la muerte.

A la mistificación de la poesía lorquiana, sobre todo en el extranjero, ha contribuido también su trágica y misteriosa muerte, que en el ámbito esloveno de los primeros años de la posguerra yugoslava tuvo fuertes connotaciones políticas, razón también por la que la imagen de la poética lorquiana ha sido frecuentemente demasiado simplificadora.

La poesía de García Lorca ha sido publicada en esloveno en varias antologías con selecciones de la mayoría de sus poemas o con traducciones de libros completos. La primera antología de la lírica española del siglo XX fue publicada durante la guerra, en 1943. Se trata del libro Moderni španski liriki (Los poetas líricos españoles modernos) cuyo autor fue Božidar Borko (traductor y periodista); el traductor principal fue el poeta modernista Alojz Gradnik, que tradujo los versos del italiano. Entre los poemas de Miguel de Unamuno, Antonio Machado, Juan Ramón Jiménez, Pedro Salinas, Gerardo Diego, Jorge Guillén y algunos otros aparecen también algunas poesías de Federico García Lorca, tomadas de Canciones y del Romancero gitano. Curiosamente la mayoría de los versos son traducidos sin rima, en verso libre, de modo que el autor de la antología concluye con la regla general de que los poetas españoles modernos prefieren el verso libre.

Para la recepción creativa de la poesía de Federico Gracía Lorca es importante sobre todo la labor traductora de Jože Udovič (1912-1986) que tradujo por primera vez los versos de García Lorca en 1947. Se sabe que Udovič conoció la poesía del poeta granadino a través de la antología francesa de Jean-Louis Schonberg.

Udovič fue también un poeta neorrealista y simbolista que buscó su expresión poética en las tensiones de los símbolos en oposición -a las visiones de la luz, belleza y pureza opone las de la oscuridad, descomposición y enajenación. Y en cuanto a la forma, Udovič suele romper con la rima y acude al verso libre. Muchos críticos, entre ellos también el traductor esloveno más productivo, Janko Moder (1958/59: 148), ven semejanzas sustanciales entre las expresiones poéticas de Udovič y de García Lorca. Parece que Udovič encontró en García Lorca un alter ego, un poeta «maldito», cuya expresión era semejante a la de su propio fuego interior. El mismo Udovič reconoce que para él la metáfora lor- 
quiana ha sido todo un descubrimiento porque con ella el poeta andaluz desvela las relaciones secretas entre los objetos, los contextos nuevos y las profundidades escondidas de la imaginación e inspiración poéticas.

De esta lectura reveladora nace la antología, publicada en 1958, con el título Pesem hoče biti luč que es la cita del primer verso de la poesía de Canciones. El canto quiere ser luz. El libro intenta acercar al lector esloveno una selección representativa de la labor poética lorquiana, por eso se publican poesías del Libro de poemas, de las Primeras canciones, de las Canciones, del Cante jondo, del Romancero gitano, del Poeta en Nueva York, del Llanto por Ignacio Sánchez Mejías y del Diván del Tamarit; además se añaden diferentes canciones y la carta de Federico García Lorca a Gerardo Diego sobre el cante jondo. Udovič escribe también un texto crítico sobre la poesía española de principios del siglo XX y unas notas que acompañan la traducción. La antología es impresionante también desde el punto de vista visual porque los versos vienen acompañados de diez dibujos de García Lorca. Fue muy bien acogida entre el público, pues se conocen varias reediciones.

Con su traducción, Udovič ofrecía al lector esloveno su propia interpretación de los versos lorquianos, de modo que en la traducción se siente la misma expresividad que en sus propios versos, sobre todo en su poemario Ogledalo sanj (El espejo de los sueños, 1961), donde más se nota la influencia del poeta granadino. Además, como Udovič era gran partidario del verso libre, todas las poesías de García Lorca en esloveno aparecen traducidas con verso libre. Algunos críticos (Novak, 2011: 131) creen que tal actitud traductora es formal y artísticamente falsa. García Lorca no es un poeta que huya del verso rimado ni que en sus intentos vanguardistas se refugie en el verso libre. Esta imagen falsa ha cambiado en 2007 con Aleš Berger, que ha traducido todo el Romancero gitano de acuerdo con las exigencias métricas del romance español. Berger ha respetando la adaptación del romance al esloveno hecha por Prešeren con el octosílabo trocaico.

La traducción de Jože Udovič en 1958 fue la primera en lengua eslovena de un poeta europeo moderno después de la Segunda Guerra Mundial cuya poética salía del marco poético esloveno de aquel entonces. Posiblemente Udovič prefirió la forma libre para poder expresar en esloveno adecuadamente las metáforas e imágenes estremecedoras, hechizantes, fascinantes de García Lorca. Quizás éste fuera el único modo con el que el traductor pudo romper la fama demasiado politizada que el poeta andaluz tuvo entre el público esloveno hasta aquel entonces. Además, habiendo sido también él mismo poeta, sintió en la poesía lorquiana la similitud expresiva y poética. Parece como si Udovič hubiera respetado la definición de la imaginación que el poeta español había dado en 1928 en su conferencia Imaginación, inspiración, evasión: «Imaginar, descubrir, llevar nuestro poco de luz a la penumbra viva donde existen todas las infinitas posibilidades, formas y números» (Cao, 1984: 61).

\section{Conclusión}

Seguramente existen más ejemplos de relaciones creativas entre la literatura española y la eslovena. Aquí se han presentado sólo unos pocos. Este tipo de «imitación» no 
disminuye en ningún momento el valor literario de la nueva obra, que de este modo puede ofrecer a sus lectores sólo una nueva dimensión literaria.

En la historia literaria eslovena casi nada se ha hablado de este tipo de enlaces con la literatura española. Tradicionalmente este tema ha sido bastante desconocido tanto para la crítica como para la historia de la literatura eslovena. Frecuentemente la literatura española ha sido calificada injustamente con la expresión un «pueblo español». En la actualidad ese vacío cultural se va llenando lentamente aunque queda todavía mucho por cambiar. Esperemos que en el futuro se publiquen más estudios sobre esos enlaces creativos y que en el futuro, gracias a un mayor número de traducciones, podamos encontrar también ejemplos de la recepción creativa de obras eslovenas en la literatura española. Por eso hay que creer que la situación hispano-eslovena actual en el campo de la creación literaria se parece a la bella descripción del amanecer en la segunda parte del Quijote:

En esto, ya comenzaban a gorjear en los árboles mil suertes de pintados pajarillos, y en sus diversos y alegres cantos parecía que daban la norabuena y saludaban a la fresca aurora, que ya por las puertas y balcones del Oriente iba descubriendo la hermosura de su rostro, sacudiendo de sus cabellos un número infinito de líquidas perlas, en cuyo suave licor bañándose las yerbas, parecía asimismo que ellas brotaban y llovían blanco y menudo aljófar. (Cervantes, 2004: II, 14, 650)

\section{BIBLIOGRAFÍA}

Cao, A. F. (1984): Federico García Lorca y las vanguardias: hacia el teatro. London: Tamesis Books Limited.

Cankar, I. (1965): Štiri drame. Ljubljana: Mladinska knjiga.

Cervantes, M. de (2004): Don Quijote de la Mancha. Madrid: Real Academia Española.

García Lorca, F. (1958): Pesem hoče biti luč. Ljubljana: Cankarjeva založba.

Kalenić Ramšak, B. (2007): «Eslovenia: recepción del Quijote». En: Carlos Alvar (ed.): Gran enciclopedia cervantina. Alcalá de Henares: Centro de Estudios Cervantinos. Madrid: Castalia, 4255-4260.

Markič, J. (2007): «Las traducciones de Don Quijote al esloveno». En: Carlos Alvar (ed.): Gran enciclopedia cervantina. Alcalá de Henares: Centro de Etudios Cervantinos. Madrid: Castalia, 4252-4255.

Moder, J. (1958/59): «García Lorca v slovenščini». En: Jezik in slovstvo, 5, 147-151.

Novak, B. A. (1995): Oblika, ljubezen jezika: recepcija romanskih pesniških oblik v slovenski poeziji. Maribor: Obzorja.

Novak, B. A. (2011): Salto immortale. Ljubljana: ZRC SAZU.

Oman, Š. (2010): «La recepción del barroco español y portugués en la poesía de France Prešeren». En: Verba Hispanica, 18, 85-102. 
Pintarič, D. (1993): «Los motivos españoles en los dramas del "ciclo español” de Andrej Hieng». En: Verba Hispanica, 3, 77-82.

Pregelj, B. (2006): «Don Quijote y la literatura eslovena». En: Branka Kalenić Ramšak, Maja Šabec (eds.): Interpretaciones del Quijote. Ljubljana: Znanstvenoraziskovalni inštitut Filozofske fakultete, 181-186.

Prešeren, F. (1969): Poezije. Ljubljana: DZS.

Prešeren, F. (2003): Cantos. Pesmi. Klagenfurt-Ljubljana-Viena: Mohorjeva družba (Hermagoras).

Prenz, J. O. (2003): «France Prešeren, poeta esloveno (1800-1849)». En: France Prešeren, Cantos. Pesmi. Klagenfurt-Ljubljana-Viena: Mohorjeva družba (Hermagoras), 170-178.

Smolej, T. (2006): «Mentions de Don Quichotte chez les écrivains slovènes jusqu'au début du xx ${ }^{\mathrm{e}}$ siècle: entre comparaison et identification». En: Branka Kalenić Ramšak, Maja Šabec (eds.): Interpretaciones del Quijote. Ljubljana: Znanstvenoraziskovalni inštitut Filozofske fakultete, 237-243.

\section{PRIMERI USTVARJALNE RECEPCIJE ŠPANSKE KNJIŽEVNOSTI V SLOVENSKEM SLOVSTVU}

Ključne besede: španska književnost, slovenska književnost, vplivi, ustvarjalna recepcija

Stiki med špansko in slovensko književnostjo so bili v duhovni zgodovini obeh narodov precej skromni. V slovenščino je bilo v preteklosti prevedenih malo španskih del, kar pa se je v drugi polovici 20. stoletja precej spremenilo. Tudi slovenski avtorji so v zadnjih letih vse več prevajani v španščino, čeprav je teh prevodov še vedno zelo malo. V slovenski literarni zgodovini in kritiki se ni veliko pisalo o vplivih španskih pisateljev na slovenske. V zadnjih dveh desetletjih pa slovenski hispanisti odkrivajo španske skrite vplive tako na slovenske pisatelje 19. stoletja (Prešeren) kot na sodobnejše avtorje. Gre za ustvarjalno recepcijo španskih tem in oblik, ki so jih slovenski avtorji vključili v svoja književna dela. Članek osvetljuje nekaj primerov ustvarjalne recepcije španske književnosti v slovenskem slovstvu, kot so Cervantesov Don Kihot, španski pesniški obliki glosa in romanca, ter pronicljiva metafora Lorcove poezije. 